\title{
Analysis on the Influence of Family Background and Cultural Capital on the Non-cognitive Skills of Children
}

\author{
Fang Luo ${ }^{1, ~ *, ~ J i a n g h u a ~ G u a n ~}{ }^{2}$, Qingli Xia ${ }^{3}$, Caihong Sun ${ }^{1}$ \\ ${ }^{1}$ School of Commerce, Huanggang Normal University, Huanggang City, China \\ ${ }^{2}$ School of Tourism Culture and Geographical Science, Huanggang Normal University, Huanggang City, China \\ ${ }^{3}$ Teaching Affairs Department, Huanggang Normal University, Huanggang City, China \\ Email address: \\ luofang68@qq.com (Fang Luo),2819343549@qq.com (Jianghua Guan), xiaqingli@yeah.net (Qingli Xia), \\ suncaihong@163.com (Caihong Sun) \\ ${ }^{*}$ Corresponding author
}

\section{To cite this article:}

Fang Luo, Jianghua Guan, Qingli Xia, Caihong Sun. Analysis on the Influence of Family Background and Cultural Capital on the Non-cognitive Skills of Children. Education Journal. Vol. 6, No. 6, 2017, pp. 188-195. doi: 10.11648/j.edu.20170606.14

Received: October 27, 2017; Accepted: November 23, 2017; Published: December 6, 2017

\begin{abstract}
The non-cognitive skills of children in family reproduction have been concerned more and more. Based on the survey of junior middle school student, we used principal component analysis to obtain the value of the index of non-cognitive skills, and further adopted the OLS method analyzing the determinants of the non-cognitive skills. It is shown that family income, parental occupations and education, participating in parent-child cultural activities, family collection of books, the grade of child, and the quality of teaching have significant and positive effect on non-cognitive skills, but taking part in an interest-oriented class and a child's gender haven't significant effect. So, the family background and the cultural capital significantly promote children's non-cognitive skills.
\end{abstract}

Keywords: Family Background, Cultural Capital, Non-cognitive Skills, Principal Component Analysis, OLS Method

\section{Introduction}

For a rich experience elder, it is easy to find that the Tenth Effect is a common phenomenon in reality. That is, not doing well on the exams in school, an ever insignificant student subsequently lives better instead, who succeeds at work and is labelled success by the society. The reason is that an academic record reflects IQ, i.e., cognitive skills more. However, the skills are multi-dimensional, in which there is an important part, i.e., non-cognitive skills besides cognitive skills. The cognitive skills were defined as the abilities of a human brain processing, storing and extracting information, i.e., the abilities of a person understanding and mastering the performance, composition, developing force, direction and law of things, and their relationship with other things [1]. The cognitive skills mainly include abilities of language, reading, writing, calculating, reasoning, etc. [2]. The concept of non-cognitive skills was put forward by American psychologist, Alexander, which was defined as psychological quality and self-restraint of a person. Although non-cognitive skills belong to the domain of non-intelligence factors, they have important influence on intelligence factors' playing a role and growing up [3]. The non-cognitive skills include self-esteem, self-control, conscientiousness, emotion, social adaptability, interpersonal skills [4], etc. From a school to society, the standards of measuring a human being are not a single one. A person with good non-cognitive skills gradually shows his multi-faced potential.

Family reproduction of children's non-cognitive skills from birth to the end of the school has aroused great concern in three different capital theories, i.e., economic capital, cultural capital and social capital [2], in which economic capital and social capital are embraced in family background. Family background is the Social Economic Status (SES) of a family, which includes family income, parental education and occupations [5], etc. Cultural capital theory was first put forward by French scholar, Bourdieu P. "Cultural capital can exist in three forms: in the embodied state, i.e., in the form of 
long-lasting dispositions of the mind and body; in the objectified state, in the form of cultural goods (pictures, books, dictionaries, instruments, machines, etc.), which are the trace or realization of theories or critiques of these theories, problematics, etc.; and in the institutionalized state, a form of objectification which must be set apart because, as will be seen in the case of educational qualifications, it confers entirely original properties on the cultural capital which it is presumed to guarantee [6]." Presently, family cultural capital doesn't have a unified definition. Ma explained as "through interaction and social practice, family members accumulate the family cultural capital, which includes how much the family possess cultural capital, such as academic certificate, cultural goods, etc., and cultural knowledge, skills and cultivation showed in practice, whether it meets the academic requirement, and its stability. Family cultural capital plays a critical guiding, promoting, or even a hindering role in the children' growth [7]." And Li interpreted as "a child exclusively occupying certain types and amount of family cultural resources [8]." We defined it as through participating in social practice and living together, family members of several generations accumulate to form the cultural resources, which refer to humanistic quality, value orientation and educational level of family members, family atmosphere, cultural facilities, etc.

Analyzing the influence of family background and cultural capital on non-cognitive skills of children, the extant literatures drew their common part, parental education, away from cultural capital, and classified in family background [9], which human intervention of cultural capital effect is too subjective and significant. Not to forcibly weaken the effect of cultural capital, we analyze the influence of family background from three dimensions, i.e., family income, parental occupations and education, and that of family cultural capital from four dimensions, i.e., participating in cultural activities, taking part in interest-oriented class, family collection of books and parental education, on non-cognitive skills. It should be noted that family background and cultural capital are concluded separately from their own three and four dimensions analyzing results, so avoiding multiple collinearity. We selected the non-cognitive skills of junior middle school students as the study objects because children' early cultivating is more effective [10]. Through the early cultivating, the non-cognitive skills of junior middle school students enter a relatively stable period. It is beneficial to survey the profound influence of family background and cultural capital on non-cognitive skills. So our findings have certain enlightening and practical guiding significance for basic education department and families.

\section{Review of Related Literature and Theoretical Hypotheses}

The reproduction of non-cognitive skills has aroused general concern, and related theoretical hypotheses [4] were tested and verified in many countries [11]. With theory of human capital underlining capability factors instead of simple education, presently, China's scholars have started paying attention to the determinants of non-cognitive skills [9], and their application in vocational development [12], innovation ability [13] and reading ability [14].

\subsection{Theoretical Evolution and Empirical Test of Non-cognitive Skills}

Based on the definition of cognitive skills, non-cognitive skills is defined as the abilities related with personality, quality and self-restraint other than cognitive skills of calculating, reading and writing. Bowles and Gintis criticized in traditional human capital theory, sure that social inequality was formed by delivering non-cognitive resources of internal family, not by inheriting cognitive skills [15]. Since then, non-cognitive skills became the focus of new human capital theory in mainstream labour economics [16]. Through studying on the General Equivalent Diploma (GED) test of American middle school, i.e., a middle school dropout can obtain a diploma by GED test, Heckman et al. found the evidence of non-cognitive skills effect on the returns to schooling [16]. The results indicated that GED recipients earn more than other dropouts, but less than general graduates because GEDs have higher cognitive skills than other dropouts but in the aspects of self-control and self-discipline are worse than general graduates. In other word, as a symbol of ability, GED signals an employer a mix message of GEDs having the same cognitive skills as general graduates, but less non-cognitive skills than general graduates [17]. Cunha et al. formulated multistage production functions for children's non-cognitive skills, whose independent variables were parental environments and investments at different stages of childhood [18]. They established nonparametric identification of a general class of production technologies based on nonlinear factor models with endogenous inputs. A by-product of this approach was a framework for evaluating childhood and schooling interventions that did not rely on arbitrarily scaled test scores as outputs and recognized the differential effects of the same bundle of skills in different tasks. They estimated the elasticity of substitution between investments in one period and stocks of skills in that period to assess the benefits of early investment in children compared to later remediation. They determined optimal targeting of interventions to children with different parental and personal birth endowments. Unlike substitutability decreasing in later stages of the life cycle in the production of cognitive skills, it was roughly constant across stages of the life cycle in the production of non-cognitive skills. Cunha et al. put forward that parental investments were generally more effective in raising non-cognitive skills other than cognitive skills [19]. Parental inputs had different effects at different stages of the child's life cycle with cognitive skills affected more at early ages and non-cognitive skills affected more at later ages. Non-cognitive skills promoted the formation of cognitive skills, but not vice versa. 


\subsection{Family Background and Non-cognitive Skills}

Family background includes family income, parental education and parental occupations [5]. Peter used propensity score methods to analyze the effect of involuntary maternal job loss on children's non-cognitive skills [20]. Based on the German Socio-Economic Panel Study (SOEP), the results showed that maternal job loss increased preschool children's socio-behavioural problems and decreased adolescents' belief in self-determination. Using data of the locus of control, reciprocity and the Big Five personality traits (openness, conscientiousness extraversion, agreeableness, and neuroticism), Anger and Schnitzlein estimated sibling correlations in non-cognitive skills to evaluate the effect of family background on skill formation, which results showed that the effect was all-around and multifaceted [21]. Using a recent US panel dataset that tracked children between grades $\mathrm{K}-5$, Fletcher and Wolfe presented new evidence of the importance of family income in the formation and evolution of children's non-cognitive skills [22]. The findings suggested an important divergence in non-cognitive skills based on family income that accumulated over time. Compared with cognitive skills, non-cognitive skills were more sensitive to changes in parental SES [23].

In addition, a few scholars proposed an oppositional opinion to the positive influence of family background on non-cognitive skills. Seemingly adverse family background may promote non-cognitive skills development. Han studied rural in southwest of Shandong province and found that due to poverty, a family was looked down upon by neighborhood or relatives, which prompted poor family's children determined to get advanced in the society [24]. They worked harder, strived to be successful, won in the competition, and wanted to prove something.

Given the above, we may put forward following proposition, different from the results of the extant literatures [9]:

Prop. 1: On the one hand, advantageous family background provides favorable conditions for children's non-cognitive skills development. On the other hand, disadvantageous family background stimulates children's non-cognitive skills development, obviously, the stimulation decreased with family background improved. So, the influence of family background on children's non-cognitive skills could be positive or negative. Two adverse strengths offset each other, the result uncertain.

\subsection{Family Cultural Capital and Non-cognitive Skills}

According to Bourdieu's three forms of cultural capital, family cultural capital also fall into three forms: the embodied state, the objectified state and the institutionalized state [25]. Family cultural capital in the embodied state is a person's cultural literacy, knowledge and skill formed through education, and family cultural atmosphere and education patterns. Family cultural capital in the objectified state includes family collection of book, learning tool, stationery commodity, etc. Family cultural capital in the institutionalized state is also called education capital, which is cultural capital affirmed by institution [26]. Family cultural capital plays an important role in education reproduction, in which cultural capital in the embodied state has bigger effect than that in the institutionalized state [27]. Tramonte and Willms divided family cultural capital into two categories: the static and the dynamic [28]. The static family cultural capital was parental cultural activities and practice that is representative of family advantage of social economy; the dynamic one was the interaction and communication patterns between parents and children that was concretely expressed as children's resources or experience, which can be strategically and successfully used for social communication by children to realize the given object. Based on data of 28 countries Program for International Student Assessment (PISA 2000), they found dynamic family cultural capital had a dramatic influence on students' reading abilities, sense of school belonging and occupational aspiration, but static family cultural capital had a moderate influence.

Parents' cultural cultivation, behavior and hobbies are passed on through children's unconscious imitation [27]. Hu's survey found that college freshmen's psychological health level showed positive correlation with parents' education, in which a mother's education appeared particularly important [29]. High education parents usually respected, tolerated, comprehended and supported children more, which was beneficial to promote children's psychological health level. Xiong et al. put forward that the cultural disadvantage of rural family influenced the children's learning motivation and academic performance in school [30]. Further even resulted in their dropping out. A family with abundant cultural capital had more cultural resources and better cultural atmosphere, so children's progress aspiration and desire were higher [31].

Through cultural capital investment, parents can directly improve children's non-cognitive skills. For example, taking part in extra-curricular activities, such as various theme summer camp or winter camp, may build up strong will and multi-interpersonal relationship, and promote their abilities of independent facing the new setting and leisured communicative competence. A family with reading and discussing atmosphere can help children develop exploring and thinking habits. A family tending to take kids to participate in cultural activities, such as visiting a museum or an art gallery, and enjoying a concert, can improve children's artistic appreciation and form their elegant temperament. A child taking part in talent and skill class, such as dance, instrument and drawing, may be selected for talent show on big occasions or competing in a contest on behalf of his class or school that contributes to increasing self-confidence. So we put forward the proposition similar to the extant literatures [9] as follows:

Prop. 2: Family cultural capital has positive impact on children's non-cognitive skills.

\section{Model Setting and Data Resources}

Firstly, according to the definition of non-cognitive skills, 
we adopt Principal Component Analysis method determining its value as an aggregative indicator of the dependent variable. And then, based on the extant literacies, we select explanatory variables (including family background and cultural capital) and control variables.

\subsection{Variables Selection}

In the following, we will analyze the determinants of non-cognitive skills from family background and cultural capital perspectives.

\subsubsection{Dependent Variable}

Dependent variable is non-cognitive skills, according to the definition, the measured variables including: a) self-esteem $\left(M_{1}\right)$; b) self-control $\left(M_{2}\right)$; c) conscientiousness $\left(M_{3}\right)$; d) love and tolerance $\left(M_{4}\right)$; e) social adaptive capacity $\left(M_{5}\right)$; and f) interpersonal skills $\left(M_{6}\right)$ [9]. Each variable is scaled by Likert's five points scale, i.e., divided by five scale: highest, higher, medium, lower and lowest, and assigned value of 5, 4, 3, 2 and 1, respectively.

We use the statistics software Stata 14. Firstly, testing the relevance of $M_{1}-M_{6}$. Their relevancies are high, in which the highest is the correlation coefficient for $M_{5}$ and $M_{6}$ of 0.531 , and the lowest is that for $M_{3}$ and $M_{6}$ of 0.319. Different from the extant literacies' principal component-factor analysis, we use principal component analysis because only this method may obtain the value of the principal component, i.e., non-cognitive skills. Secondly, the principal component analysis of $M_{1}-M_{6}$. The results of principal component analysis through correlation coefficient matrix are shown in Table 1 and Table 2. As shown in Table 1, only the eigenvalue of the principal component Comp 1 exceeds 1 , and its contribution rate is up to 0.811 . As shown in Table 2, Comp 1 fully explains variables $M_{l}-M_{6}$. So, Comp 1, i.e., non-cognitive skills aggregative indicator $(Y)$ may be represented as

$$
Y=0.48 M_{1}+0.498 M_{2}+0.514 M_{3}+0.511 M_{4}+0.54 M_{5}+0.505 M_{6} .
$$

In addition, scree plot (omitted) also shows that from Comp 2, the change trend of eigenvalues tends to be stable. Lastly, testing the adequacy of principal component analysis. According to the program of statistics software Stata, the adequacy is tested after principal component analysis [32]. The Kaiser-Meyer-Olkin (KMO) measure of sampling adequacy is shown in Table 3. Overall KMO value is 0.835 that shows the principal component analysis works well.

Table 1. Eigenvalue and its contribution rate.

\begin{tabular}{lllll}
\hline Principal component & Eigenvalue & Difference & Proportion & Cumulative \\
\hline Comp 1 & 5.059 & 2.328 & 0.811 & 0.811 \\
Comp 2 & 0.432 & 0.074 & 0.069 & 0.881 \\
Comp 3 & 0.319 & 0.025 & 0.051 & 0.932 \\
Comp 4 & 0.201 & 0.113 & 0.032 & 0.964 \\
Comp 5 & 0.124 & 0.118 & 0.020 & 0.984 \\
Comp 6 & 0.101 & - & 0.016 & 1.000 \\
\hline
\end{tabular}

Table 2. Loading of the principal component.

\begin{tabular}{|c|c|c|c|c|c|c|c|}
\hline Variables & Comp 1 & Comp 2 & Comp 3 & Comp 4 & Comp 5 & Comp 6 & Unexplained \\
\hline$M_{1}$ & 0.480 & 0.452 & -0.003 & 0.800 & 0.075 & 0.078 & 0 \\
\hline$M_{2}$ & 0.498 & 0.225 & 0.717 & -0.307 & 0.274 & -0.330 & 0 \\
\hline$M_{3}$ & 0.514 & 0.346 & -0.196 & -0.458 & -0.397 & 0.474 & 0 \\
\hline$M_{4}$ & 0.511 & -0.088 & -0.605 & -0.188 & 0.622 & -0.188 & 0 \\
\hline$M_{5}$ & 0.540 & -0.326 & -0.130 & 0.085 & -0.605 & -0.557 & 0 \\
\hline$M_{6}$ & 0.505 & -0.658 & 0.255 & 0.117 & 0.093 & 0.562 & 0 \\
\hline
\end{tabular}

Table 3. KMO testing.

\begin{tabular}{ll}
\hline Variables & KMO \\
\hline$M_{1}$ & 0.887 \\
$M_{2}$ & 0.843 \\
$M_{3}$ & 0.816 \\
$M_{4}$ & 0.860 \\
$M_{5}$ & 0.822 \\
$M_{6}$ & 0.800 \\
Overall & 0.835 \\
\hline
\end{tabular}

\subsubsection{Explanatory Variables}

Explanatory variables include two types of characteristic variables, i.e., family background characteristic variables and cultural capital characteristic variables. Family background characteristic variables include family incomes $\left(D_{2}, D_{3}\right)$, parental occupations $\left(D_{4}, D_{5}\right)$ and parental education $\left(D_{6}\right)$. Family income is roughly classified as three grades: high, middle and low. $D_{2}$ takes the value of 1 for middle income, otherwise taking the value of 0 , and $D_{3}$ takes the value of 1 for high income, otherwise taking the value of 0 , in which low income family is the reference category. Parental occupations follow the principle of "for up not for down", that is, taking whichever is the higher because the higher one represents the family can achieve the highest social economic status and have the corresponding social resources. According to the research of Hou, the occupations fall into three categories: white-collar worker class (including staffs of government departments and public institutions, middle and senior executives of company, teacher, engineer, doctor, lawyer, etc.), blue-collar worker class (including skilled worker, ordinary worker of production industry and business and service, self-employed businessman, etc.), and farmer or unemployed class [33]. $D_{4}$ takes the value of 1 for the blue-collar worker 
class, otherwise taking the value of 0 , and $D_{5}$ takes the value of 1 for the white-collar worker class, otherwise taking the value of 0 , in which the farmer or unemployed class is the reference category. Parental education follows the principle of "for up not for down", that is, taking whichever is the higher because the higher one represents the family's cultural level. The education is classified as two grades: junior colleague or above, and junior colleague below [9]. $D_{6}$ takes the value of 1 for the junior colleague or above, otherwise taking the value of 0 , in which the junior colleague below is the reference category. According to the review of section 2.2 and Prop. 1, we predict the signs of $D_{2}-D_{6}$ are uncertain.

Based on Ji classifying China's cultural capital [25], we select the family cultural capital characteristic variables that including parental education $\left(D_{6}\right)$, cultural activities participation $\left(D_{7}\right)$, interest, talent and skill class training $\left(D_{8}\right)$, and family collection of books $\left(D_{9}\right)$. The explanation of the parental education see above. The cultural activities participation means parents and children going to a bookstore or a library reading together, visiting a museum or a science and technology hall, going out watching a show, travelling [29], etc. $D_{7}$ takes the value of 1 for often participating in cultural activities, otherwise taking the value of 0 , in which not often is the reference category. The interest, talent and skill class training means children registering for those extra-curricular classes, such as training dancing, instrument, drawing, sports, Mathematical Olympiad, English, etc. $D_{8}$ takes the value of 1 for registering for the extra-curricular classes, otherwise taking the value of 0 , in which not registering is the reference category. $D_{9}$ takes the value of 1 for family collection of books large, otherwise taking the value of 0 , in which not large is the reference category. According to the review of section 2.3 and Prop. 2, we predict the signs of $D_{7}-D_{9}$ are positive.

\subsubsection{Control Variables}

Previous researches have shown that gender $\left(D_{10}\right)$ [34], grade $\left(D_{11}, D_{12}\right)$ [35], school education quality and spirit $\left(D_{13}\right.$, $D_{14}$ ) [21], etc., have impacts on students' non-cognitive skills. With the grade or school-running level increasing, the students' non-cognitive skills are improved [21] [35]. So we predict the signs of $D_{11}-D_{14}$ are positive. Under the precondition of other situations similar, schoolboys outperform schoolgirls in independence, innovation, tolerance, etc., while schoolgirls outperform schoolboys in endurance, self-control, conscientiousness [36], etc. So the effect of gender is uncertain.

The name, sign prediction, mean and standard deviation of the above variables are shown in Table 4.

Table 4. The variables description.

\begin{tabular}{|c|c|c|c|c|c|}
\hline Variable type & Variable name & Mean & Std. dev. & Description & Sign prediction \\
\hline Dependent variable & Non-cognitive skills (Y) & 12.049 & 1.897 & Quantitative variable. & \\
\hline \multirow{7}{*}{$\begin{array}{l}\text { Family background } \\
\text { characteristic variables }\end{array}$} & Family income & & & $D_{2}=1$, middle income; 0 , otherwise. $D_{3}=1$, high & \\
\hline & $\mathrm{D}_{2}$ & 0.721 & 0.449 & income; 0 , otherwise. Reference category is low &,+- \\
\hline & $D_{3}$ & 0.071 & 0.257 & income. &,+- \\
\hline & Parental occupations & & & $D_{4}=1$, blue-collar worker class; 0 , otherwise. $D_{5}=1$, & \\
\hline & $D_{4}$ & 0.420 & 0.494 & white-collar worker class; 0 , otherwise. Reference &,+- \\
\hline & $D_{5}$ & 0.227 & 0.420 & category is farmer or unemployed class. &,+- \\
\hline & Parental education ${ }^{\#}$ & & & $D_{6}=1$, junior colleague or above; 0 , otherwise. & \\
\hline \multirow{5}{*}{$\begin{array}{l}\text { Family cultural capital } \\
\text { characteristic variables }\end{array}$} & $\begin{array}{l}D_{6} \\
\text { Cultural activities }\end{array}$ & 0.268 & 0.444 & Reference category is junior colleague below. &,+- \\
\hline & participation & 0271 & 0445 & $\begin{array}{l}D_{7}=1 \text {, often; } 0 \text {, otherwise. Reference category is not } \\
\text { often. }\end{array}$ & + \\
\hline & Extra-curricular classes & & & $D_{8}=1$, registering; 0 , otherwise. Reference category is & \\
\hline & $\begin{array}{l}D_{8} \\
\text { Family collection of books }\end{array}$ & 0.401 & 0.491 & $\begin{array}{l}\text { not registering. } \\
D_{9}=1, \text { large; } 0 \text {, otherwise. Reference category is not }\end{array}$ & + \\
\hline & $D_{9}$ & 0.401 & 0.491 & large. & + \\
\hline \multirow[t]{7}{*}{ Control variables } & $\begin{array}{l}\text { Gender } \\
D_{10}\end{array}$ & 0.498 & 0.501 & $\begin{array}{l}D_{10}=1 \text {, schoolboys; } 0 \text {, otherwise. Reference category } \\
\text { is schoolgirls. }\end{array}$ &,+- \\
\hline & Grade & & & $D_{I I}=1$, grade two of junior high school; 0 , otherwise. & + \\
\hline & $D_{l I}$ & 0.152 & 0.360 & $D_{12}=1$, grade three of junior high school; 0 , otherwise. & \\
\hline & $D_{12}$ & 0.286 & 0.453 & & + \\
\hline & $\begin{array}{l}\text { School education quality } \\
\text { and spirit }\end{array}$ & & & $D_{13}=1$, ordinary; 0 , otherwise. $D_{14}=1$, good; 0 , & \\
\hline & $D_{13}$ & 0.342 & 0.475 & otherwise. Reference category is bad. & + \\
\hline & $D_{14}$ & 0.613 & 0.488 & & + \\
\hline
\end{tabular}

Notes: ${ }^{\#}$ Parental education belongs to family cultural capital characteristic variables, either.

\subsection{Estimation Method and Data Resources}

Because the dependent variable $(Y)$ is a continuous quantitative variable, we use Ordinary Least Squares (OLS) method estimating the model. The data comes from the investigation on internet in June and July, 2017. The questionnaire is issued on "Questionnaire Star", the platform of survey-test-vote. There are 269 valid questionnaires received, which come from 37 cities, such as Wuhan, Changsha, Xinxiang, Nanchang, Shenzhen, etc., in 16 States/Provinces, such as Hubei, Hunan, Anhui, Beijing, Jiangsu, etc. 


\section{Regression Results Analysis}

The regression results are shown in Table 5. The $\mathrm{F}$ statistic value of model overall significance test is 3.954 with a probability of 0.0000 . It is significant at the significance level of $1 \%$ that means the regression modeling is valid as a whole. The coefficient of determination is 0.792 , and the adjusted coefficient of determination is 0.701 . The model explains $79.2 \%$ of the variation of the dependent variable, so the explanatory power of the model is good.

Table 5. The results of OLS estimation.

\begin{tabular}{lllll}
\hline Y & Coef. & Std. err. & $\mathbf{t}$ & $\mathbf{P}>|\mathbf{t}|$ \\
\hline Cons. & $10.765^{* * *}$ & 0.580 & 18.551 & 0.000 \\
$D_{2}$ & $0.240^{*}$ & 0.308 & 1.664 & 0.094 \\
$D_{3}$ & $0.289^{*}$ & 0.516 & 1.678 & 0.089 \\
$D_{4}$ & 0.170 & 0.288 & 0.590 & 0.556 \\
$D_{5}$ & $0.821^{*}$ & 0.435 & 1.888 & 0.060 \\
$D_{6}$ & $0.582^{*}$ & 0.351 & 1.658 & 0.099 \\
$D_{7}$ & $0.550^{* *}$ & 0.337 & 2.133 & 0.041 \\
$D_{8}$ & -0.055 & 0.268 & -0.204 & 0.839 \\
$D_{9}$ & $0.376^{*}$ & 0.303 & 1.684 & 0.082 \\
$D_{10}$ & 0.341 & 0.223 & 1.531 & 0.127 \\
$D_{I 1}$ & $0.467^{* *}$ & 0.330 & -2.144 & 0.033 \\
$D_{I 2}$ & $0.707^{*}$ & 0.257 & -1.815 & 0.071 \\
$D_{13}$ & 0.625 & 0.560 & 1.116 & 0.265 \\
$D_{14}$ & $1.106^{* *}$ & 0.554 & 1.995 & 0.047 \\
Obs & 269 & & & \\
$\mathrm{~F}$ & 3.954 & Prob>F & $0.000^{* * *}$ & \\
$\mathrm{R}^{2}$ & 0.792 & $\overline{\mathrm{R}}^{2}$ & 0.701 & \\
\hline
\end{tabular}

Notes: ${ }^{*},{ }^{* *}$ and ${ }^{* * *}$ show significance at significant level of $10 \%, 5 \%$ and $1 \%$, respectively.

\subsection{Non-cognitive Skills and Family Background}

Family incomes $\left(D_{2}, D_{3}\right)$ are significant at the significance level of $10 \%$, and the signs are all positive. The results show that the higher the family income, the stronger the children's non-cognitive skills. At the significance level of $10 \%, D_{5}$ is significant, but $D_{4}$ isn't. The sign of $D_{5}$ is positive. It is shown that compared with the non-cognitive skills of children whose parent is a farmer or unemployed, those of children whose parent is a white-collar worker are significantly higher, while those of children whose parent is a blue-collar worker have no significant difference with them. Parental education $\left(D_{6}\right)$ is significant at the significance level of $10 \%$, and its sign is positive, which shows that the higher the parental education, the stronger the children's non-cognitive skills.

In conclusion, the family background has positive influence on children's non-cognitive skills, which is consistent with the results of the extant researches [9]. Prop. 1 puts forward that on the one hand, advantageous family background provides favorable conditions for children's non-cognitive skills development; on the other hand, disadvantageous family background stimulates children's non-cognitive skills development. The regression results show that the facilitating effect of advantageous family background on children's non-cognitive skills significantly exceeds the stimulating effect of disadvantageous family background.

\subsection{Non-cognitive Skills and Family Cultural Capital}

Cultural activities participation $\left(D_{7}\right)$ is significant at the significance level of $5 \%$, and the sign is positive. Compared with not often participating in cultural activities, often participating in significantly improves children's non-cognitive skills. Interest, talent and skill class training $\left(D_{8}\right)$ is not significant, which seems that the parents don't want to see. The parents have spent a lot of time, energy and money to send the children to various excellent training classes or art and skill classes, but they don't achieve the desired results. It is mainly because most parents don't proceed from the children's strong point or interest, but swimming with the tide, i.e., following the others steps while they register for the interest-oriented classes for their children. That it produces very little effect is almost inevitable. Family collection of books $\left(D_{9}\right)$ is significant at the significance level of $10 \%$, and the sign is positive. Compared with a family not rich in books, a family rich in books significantly promotes the children's non-cognitive skills. In addition, parental education $\left(D_{6}\right)$ is significant at the significance level of $10 \%$, and its sign is positive.

In conclusion, the family cultural capital has positive influence on children's non-cognitive skills, which is consistent with the results of the extant researches [9]. Meanwhile Prop. 2 is proved.

\subsection{The Effect of Control Variables}

Gender $\left(D_{10}\right)$ is not significant. As the extant literacies suggested, schoolboys outperformed schoolgirls in independence, innovation, tolerance, etc., while schoolgirls outperformed schoolboys in endurance, self-control, conscientiousness [36], etc. In our research, two adverse strengths are almost equal, i.e., no one strength significantly exceeds another, which offsets each other that makes the influence of gender on non-cognitive skills un-significant. Grade two of junior high school $\left(D_{11}\right)$ and grade three of junior high school $\left(D_{12}\right)$ are significant at the significance level of $5 \%$ and $10 \%$, respectively, and the signs are all positive. Compared with the grade one of junior high school students, the grade two and three of junior high school students are significantly improved in non-cognitive skills, which shows that non-cognitive skills increase with grades because education not only increases students' language, reading, writing abilities [2], but also non-cognitive skills. Ordinary school education quality and spirit $\left(D_{13}\right)$ is not significant, and its sign is positive, though. Good school education quality and spirit $\left(D_{14}\right)$ is significant at the significance level of $5 \%$, and its sign is positive. Compared with the bad school education quality and spirit, the good one significantly promotes students' non-cognitive skills, while the ordinary one slightly promotes, but not significantly. Good school education quality and spirit makes the students achieve comprehensive development because surrounding environmental factors including campus environment, teachers, schoolfellows, etc. all provide the nutrients for their thriving. 


\section{Important Conclusions and Policy Implications}

According to the above regression results, it is not difficult to draw the following conclusions: (1) Facilitating effect of advantageous family background on children's non-cognitive skills significantly exceeds stimulating effect of disadvantageous family background. With the family background (including family income, parental occupation and parental education) improved, the children's non-cognitive skills increase. (2) The family cultural capital has positive influence on children's non-cognitive skills. Cultural activities participation, family collection of books and parental education significantly promote the children's non-cognitive skills, but interest, talent and skill class training doesn't. (3) The students' non-cognitive skills increase with their grades. (4) School education quality and spirit has significant influence on children's non-cognitive skills development.

The policy implications of the above conclusions are: (1) Parents are not only the first teacher of children, but also the lifelong teacher; Family is not only the first class in life, but also the lifelong class. As parents, they should have the ideology of "live and learn", growing up with the children. In this age of knowledge explosion, if a person doesn't study for three months, his knowledge structure will get stale and be out of date. Parents who don't persist in learning won't be excellent employees in work units and will have difficulty winning promotion, so they can't improve the family's SES. In the meantime, the parents don't know the children's circumstances, interests and hobbies, so they can't correctly guide the children whose mind doesn't develop well how to face life with a positive and sunny mindset. (2) Parents and children often participate in cultural activities, such as visiting an exhibition, go out watching a show, travel, etc., which is extremely helpful for improving children's cognitive skills. For parents who work a lot or live a stressful material life, they should especially pay attention to this kind of parent-child activities because those pass on an important message to children, i.e., parents come along with children to the cultural activities even if they are busy with work or money was tight for the family, which indicates parents value their children. So, the children's innocent hearts harvest full love and happiness, which will be an inexhaustible motive force for their aggressiveness in the life. (3) The family collects not only humanities and social sciences books, but also professional books helpful for family members' working or studying. All family members form habits of loving reading and reading good books, and they naturally abandon the modern entertainment which is very time consuming but not benefiting improving their accomplishment and abilities. (4) Registering for the interest-oriented class should proceed from the children's interests, hobbies and specialties. Lacking of their own wills and "following the fashion" without judging are not only a waste of resources, but also an inhibition of children's natural growth. The children gain little because they are not interested in the learning contents, which will make them be fooled into thinking that they are stupid. Once this concept is formed, the children's life patterns are constrained. (5) Good school education quality and spirit help students to win at the beginning of the life, but high-quality educational resources are scarce. So, the China's government should break the educational bottleneck from following four respects: Firstly, the government should set up a system of national compulsory education quality monitoring, guaranteeing the compulsory education balanced development, and realizing the education quality comprehensive improvement. Secondly, the government should set up a concept of justice oriented, making the compulsory education shift from excessive going after quantity and efficiency to paying attention to balance and justice. Thirdly, the government should promote the reform of public finance system, shouldering the responsibility of the compulsory education balanced development. Lastly, the government should establish a mechanism of diversified education supply, exerting the function of social benefits [37].

\section{Acknowledgements}

This work was supported by Huanggang Normal University Projects (No. zxfz2016B033 and No. 2016CE25).

\section{References}

[1] Y.-j. Meng, "Cognitive abilities and household portfolio choice," Economic Research Journal, 2014, (S1), pp. 132-142. (in Chinese).

[2] G. Farkas, "Cognitive Skills and noncognitive traits and behaviors in stratification processes," Annual Review of Sociology, 2003, 29, pp. 541-562.

[3] C.-t. Zhang, "Quality: Meditation on China's education," Wuhan: Huazhong University of Science and Technology Press, 2001. (in Chinese).

[4] F. Cunha, J. J. Heckman, and S. Navarro, "Separating uncertainty from heterogeneity in life cycle earnings, the 2004 Hicks lecture," Oxford Economic Papers, 2005, 57(2), pp. 191-261.

[5] O. D. Duncan, D. L. Featherman, and B. Duncan, "Socioeconomic background and achievement," New York: Seminar Press, 1972.

[6] P. Bourdieu, "The forms of capital (R. Nice, Trans.)," In J. Richardson (Ed.), Handbook of theory and research for the sociology of education, New York: Greenwood, 1986.

[7] L.-q. Ma, "The relationship between rural family cultural capital and junior middle school English learning outcomes," Chong Qing: Southwest University, 2008. (in Chinese).

[8] M.-c. Li, "Theoretical study on the influence of family cultural capital on the education chance of senior high school students," Shen Yang: Shen Yang Normal University, 2008. (in Chinese).

[9] L. Li and W.-1. Zhao, "Research on the influence of family background and cultural capital on the cognitive skills and non-cognitive skills," Dongyue Tribune, 2017, 38(4), pp. 142-150. (in Chinese). 
[10] Y.-j. Liang, "Family cultural capital for investment in early childhood affect interest in reading," Chengdu: Sichuan Normal University, 2016. (in Chinese).

[11] S. Brown, S. McIntosh, and K. Taylor, "Following in your parents' footsteps? Empirical analysis of matched parent offspring test scores," Oxford Bulletin of Economics and Statistics, 2011, 73(1), pp. 40-58.

[12] G.-f. Sun and Y. Zhang, "An empirical analysis on the influence of non-cognitive ability cultivation on the development of engineers' occupation," Research in Higher Education of Engineering, 2014, (4), pp. 43-49. (in Chinese).

[13] H.-b. Sun, "Analysis on the training of non-cognitive factors and innovation ability of students," Yantai Normal University Journal (Philosophy and Social Sciences Edition), 2004, 21(1), pp. 115-117. (in Chinese).

[14] N. Fan, "The influence of non-cognitive factors on reading ability," Journal of Adult Education College of Hebei University, 2010, 12(1), pp. 98-99. (in Chinese).

[15] S. Bowles and H. Gintis, "Schooling in capitalist America: Educational reform and the contradictions of economic life," New York: Basic Books, 1976.

[16] J. J. Heckman, J. J. Hsse, and Y. Rubinstein, "The GED is a mixed signal: The effect of cognitive and non-cognitive skills on human capital and labor market outcomes," University of Chicago Xerox, 2000.

[17] J. J. Heckman and Y. Rubinstein, "The importance of noncognitive skills: Lessons from the GED testing program," The American Economic Review, 2001, 91(2), pp. 145-149.

[18] F. Cunha, J. J. Heckman, and S. M. Schennach, "Estimating the technology of cognitive and noncognitive skill formation," Econometrica, 2010, 78(3), pp. 883-931.

[19] F. Cunha and J. J. Heckman, "Formulating, identifying and estimating the technology of cognitive and noncognitive skill formation," Journal of Human Resources, 2008, 43(4), pp. 738-782.

[20] F. Peter, "The effect of involuntary maternal job loss on children's behaviour and non-cognitive skills," Labour Economics, 2016, 42, pp. 43-63.

[21] S. Anger and D. D. Schnitzlein, "Cognitive skills, non-cognitive skills, and family background: Evidence from sibling correlations," Journal of Population Economics, 2017, 30(2), pp. 591-620.

[22] J. M. Fletcher and B. Wolfe, "The importance of family income in the formation and evolution of non-cognitive skills in childhood," Economics of Education Review, 2016, 54, pp. 143-154.

[23] A. Hsin and Y. Xie, "Life-course changes in the mediation of cognitive and non-cognitive skills for parental effects on children's academic achievement," Social Science Research, 2017, 63, pp. 150-165.

[24] Y. Han, "The influence of family traditional cultural capital on rural youth transcending class," Youth Exploration, 2016, (2), pp. 46-54. (in Chinese).

[25] X.-y. Ji, "On the influence of family cultural capital on the development of junior middle school student's ideology and morality," Journal of Xiangyang Vocational and Technical College, 2014, 13(2), pp. 95-97. (in Chinese).

[26] Q. Wang, "Rural students' English learning dilemma and its transformation strategy research," Education and Teaching Research, 2014, 28(5), pp. 14-17. (in Chinese).

[27] Y. Yang, "The impact of family cultural capital on academic achievement: Based on the empirical analysis of PISA-2012," Modern Education Science, 2016, (6), pp. 56-61. (in Chinese).

[28] L. Tramonte and J. D. Willms, "Cultural capital and its effects on education outcomes," Economics of Education Review, 2010, 29(2), pp. 200-213.

[29] S.-f. Hu, "On the effect of the family's cultural capital on college freshmen's mental health," Chinese Journal of Special Education, 2016, (9), pp. 78-83. (in Chinese).

[30] J. Xiong, T. Shan, and M.-j. Qian, "Analysis on the behavior of rural adolescents dropping out," China Youth Study, 2016, (3), pp. 49-55. (in Chinese).

[31] P. Bourdieu and J.-C. Passeron, "Reproduction in Education, Society and Culture," London: Sage Publication, 1990.

[32] B. Hu, R. Lui, W.-d. Ding, et al., "Stata statistic analysis and application," Rev. ed, Beijing: Electronic Industry Press, 2013. (in Chinese).

[33] L.-m. Hou, "The relative risk aversion or the credential decline aversion? A reconsideration of the generation mechanism of China's educational inequality," Sociological Studies, 2015, (2), pp. 192-213. (in Chinese).

[34] M. Gensowski, J. Heckman, and P. Savelyev, "The effects of education, personality, and IQ on earnings of high-ability men," The American Economic Association Meetings, Chicago, 2012.

[35] P. Carneiro, K. T. Hansen, and J. J. Heckman, "Estimating distribution of treatment effects with an application to the returns to schooling and measurement of the effects of uncertainty on college," The National Bureau of Economic Research, Working Paper No. 9546, 2003.

[36] J.-q. Liu, "Education in Accordance with Gender Characters," Education Teaching Forum, 2017, (9), pp. 51-52. (in Chinese).

[37] J. Jin, "The education justice and efficiency of selecting a school," Popular Literature (Theory), 2009(4), pp. 182-183. (in Chinese). 